\title{
A Literature Review on the Supply Chain Coordination of the Buyback Contract
}

\author{
Zhang Nan ${ }^{1,2, a}$, Zhou Zong Fang ${ }^{1, b}$ \\ ${ }^{1}$ School of Management and Economics, University of Electronic Science and Technology of China, \\ Chengdu, 611731, China \\ ${ }^{2}$ College of Fundamental Studies, Sichuan Normal University, Chengdu, 610068, China \\ aemail: zhangnan@sicnu.edu.cn, bemail: zzf1020@aliyun.com
}

Keywords: supply chain coordination; buyback contract

\begin{abstract}
Buyback contracts are widespread in supply chain coordination under various situations and have drawn for many years the attention of the researchers. This paper gives an introduction to the buyback contracting literature by classifying these research literatures into three parts according to the structure of supply chain (a supply chain consists of one upstream supplier and one downstream retailer; a supply chain with multiple suppliers and one retailer; a supply chain with multiple suppliers and multiple retailers). At last, some suggestions concerning the future research are proposed.
\end{abstract}

\section{Introduction}

Due to the double marginalization that exists in the decentralized decision-making, many researchers focus on the coordination of supply chain, which aims at improving supply chain performance by aligning the plans and the objective of upstream suppliers-downstream retailers. From the perspective of supply chain structure, supply chain coordination models may involve three categories: a supply chain consists of one upstream supplier and one downstream retailer; a supply chain with multiple suppliers and one retailer; a supply chain with multiple suppliers and multiple retailers. Otherwise, these coordination models may also involve inventory theory, multiple decision makers, asymmetric information, as well as paradigms of manufacturing, such as mass customization, short product life-cycles, outsourcing and delayed differentiation. Almost all coordination mechanisms are based chiefly on the contract theory. There are varieties of coordination contracts, such as two-part tariff, sales rebate, quantity discount, and buyback, etc.

Buyback contracts are widespread in supply chain coordination under various situations, in the newspapers, book, CD and fashion industries, and have drawn for many years the attention of the researchers. With these types of contracts, the suppliers commit to buy back remaining obsolete inventory at a discounted price from the retailers. In doing this, the upstream suppliers give the downstream retailers a clear guarantee to guide them to improve order quantity and inventory level. [1][2].

This paper systematically reviews the research results on buyback contracts in recent years, aims at enable readers to get the knowledge of existing research on supply chain coordination. The rest of the paper is organized as follows. In Section 2, review the literature on the coordination of supply chain consisting of one upstream supplier and one downstream retailer (hereafter referred as one-one supply chain) by using buyback contracts. Subsequently, Section 3 reviews the literature on the coordination of supply chain where one upstream supplier sells its product to multiple downstream retailers (hereafter referred as one-multi supply chain). The coordination of supply chain where multiple upstream firms sell their products to a downstream retailer (hereafter referred as multi-one supply chain) is reviewed in Section 4. Finally, Section 5 summarizes the directions of future research. 


\section{Coordination on one-one supply chain by using buyback contract}

Many researchers consider this classical one-one supply chain setting. In this basic setting, the downstream retailer, who often faces uncertainties demand, typically orders fewer products than the optimal order quantity for the centralized system, which negatively affects the supply chain performance. Then the upstream supplier shares the inventory risk with this offering that he will buy back the remaining obsolete inventory at a discounted price.

Xiong et al. [3] have considered a two-stage supply chain with an upstream manufacturer and a downstream retailer, and then, introduced a composite contract by organically combining two component contracts: a buyback contract and a quantity flexibility contract. They have showed that as long as one of the buyback contract and the quantity flexibility contract can coordinate the supply chain, so can the composite contract; moreover, when some contract parameters are constrained, they have fined where the composite contract coordinates the supply chain even if the two component contracts cannot. Wei and Tang [4] have analyzed coordination of a Stackelberg game model based on the buyback contract predominated by the supplier, and obtained the Nash equilibrium solution to this model when wholesale price and maximum buyback rate are determined by the supplier and the order quantity is determined by the retailer with respect to the stochastic market demand. This paper has indicated that when the supplier is in the leading role, he can determine the proportion or relation of risks shared by supply and demand parties. As a constraint condition, the proportion or relation the risk is of guiding significance for determination of maximum buyback proportion. Yao et al. [5] have presented an analytical model and then used numerical methods with the Stackelberg game to analyse the impact of stochastic and price dependent demand on buyback contract in a single-period product supply chain. Qin et al. [6] have realized that supply chain decision makers are not completely rational and their behavior will be affected by some factor such as fairness preference, loss aversion, sympathy, disgust and so on, but most of the present articles about supply chain did not consider fairness preference. Based on this, their paper draw the fairness preference into buyback contract, according to the Nash bargaining game, we establish a framework and functions of utility about fairness preference to study the coordination of buyback contract; we also carry out the sensitivity analysis about wholesale price, retail price, cost and buy back price. The most important finding in their paper is that even when the supplier doesn't know the retailer's degree of fairness preference, he can also design a wholesale price and a buyback price to achieve the best profits or utility. Lei et al. [7] have considered returns policies under which consumers' valuation depends on the refund amount they receive and the length of time they must wait after the item is returned. Based on the analysis of consumer return behavior on a traditional buyback contract, the authors have introduced a new differentiated buyback contract depending on return deadline, and this contract enables to coordinate a supply chain consisting of an upstream manufacturer and a downstream retailer. Shen et al. [8] have proposed an incentive-compatible wholesale-buyback contract to coordinate the channel for any retail cost in a manufacture-retail system with private retail cost information. Chen et al. [9] have proposed a buyback contract that include two buyback prices (one for unsold inventory and a second for customer returns) between the manufacturer and the retailer where the retailer simultaneously determines the retail price and order quantity while experiencing customer returns and price dependent stochastic demand. The authors have showed that this type of easy-to-implement agreement can achieve perfect supply chain coordination and be a win-win for both manufacturer and retailer when a complementary profit-sharing agreement is included. Xiao et al. [10] have investigates coordination of a supply chain consisting of one manufacturer and one retailer facing consumer return. They have integrated consumer returns policy and manufacturer buyback policy within a modeling framework and explicitly model the positive effect of refund amount on demand and its negative effect on the probability that consumers keep the products. Moreover, they have then designed a buyback/markdown money contract to coordinate the supply chain under partial refund policy and find that the refund amount plays an important role in the decisions and profitability of the players. In the coordinated setting with given buyback price, the refund amount first increases the players' expected profits/quantity, and then decreases them. When 
the risk (variance) of the consumer's valuation increases, the manufacturer may raise the unit wholesale price to achieve a higher unit profit. The supply chain is better off using full refund policy if the risk is very small; otherwise, the supply chain prefers on returns policy. The results of this paper are robust to distribution form. Wu [11] has examined the impact of buyback policy on retail price, order quantity and wholesale price in a duopoly of two manufacturer-retailer supply chains under the competing supply chain framework. The author has showed that channel coordination can be achieved by utilizing buyback contracts in two supply chains, and the analysis has demonstrated that buyback contract can lead to a high profit than non-buyback in both Vertical Integration and Manufacturer's Stackelberg. Yan [12] have constructed a reverse chain system with one manufacturer and one retailer under demand uncertainties, and used buyback contract as coordination mechanism in a reverse supply chain. They author have concluded that the reverse supply chain system could be coordinated if the quality differences between the new products and the remanufactured products have been ignored. Lokendra et al. [13] have designed a individually rational buyback contract that coordinate the supply chain when the retailer faces inventory-level-dependent demand and any leftover inventory at the retailer can be returned to the supplier at a pre-specified terms. Güler \& Keskin [14] have studied the coordination ability of the buyback contract in a supply chain with random yield and random demand(SCRYRD). The authors have shown that the randomness in the yield does not change the contract's coordination ability but affect the values of the contract parameters, and shown that the buyback contract is able to coordinate the supply chain under voluntary compliance. Li et al. [15] have respectively developed two stochastic models for centralized channel and decentralized channel to handle new fashion and off-season product sales. They have investigated optimal pricing and order policies in supply chain management of fashion products (e.g., a fashion apparel category) with consideration of product returns between supply chain partners (B2B). The authors have proposed the Stackelberg game model in the decentralized channel to derive the optimal Stackelberg equilibrium solution and then designed a buyback contract to coordinate the channel. The authors are motivated by the actuality of supply chain channel issues in the fashion product industry, especially in the clothing industry. He et al. [16] have found that a modified buyback and profit guarantee contracts can provide significant Pareto improvement over Push or Advance-purchase discount(APD) contracts when the manufacturer is risk-neural and the retailer is satisficing, while revenue-sharing contract cannot. In contrast, revenue sharing and modified buyback contracts is Pareto dominant under certain conditions when the manufacturer is satisficing and the retailer is risk-neutral. Ping et al. [17] have studied the supply chain coordination issue with a supplier and a retailer that uses group buying mechanism when selling to customers. The authors have found that a buyback contract can coordinate the supply chain under group buying, and demonstrated how its contract terms critically depend on the quantity threshold above which group buying deal is activated. Wang and Wang [18] created a supply chain coordination model under fuzzy demand and proved that the supply chain can be coordinated by a adjusting the parameters of a buyback contract.

\section{Coordination on one-multi supply chain by using buyback contract}

Özen et al. [19] have extended a distribution system model that consists of a manufacturer, a warehouse (or a distribution center), and $\mathrm{n}$ retailers. Each retailer sells an identical product, made by the manufacturer. Due to long production and transportation lead times, they have to place their orders without knowing the exact value of the demand, but they have information about its distribution. The orders arrive at a warehouse after some production and transportation lead-time elapses, during which time the retailers update their demand forecasts by receiving separate demand signals. The authors have analyzed coordination of this distribution system with updated demand information through buyback contracts, and concluded that a system-optimal solution can only be achieved with an appropriate selection of the buy-back price when the signal reveals the exact demand realization and the retailers are symmetric.

Sediri and Nakade [20] have developed a buyback contract model of the competitive newsvendor problem between a single supplier and multiple retailers under simultaneous price and safety stock 
competition, and in this model, safety-stock is added. To translate the price and safety stock competition respectively, a price completion factor and a spill rate is constructed. Then, they have computed we compute Nash equilibrium prices, safety stocks, optimal wholesale, optimal supplier and retailers' profits, numerically, and discussed the effect of competition and distribution parameters and compared to that of the non-competitive model and chain optimization.

Huang et al. [21] have developed a unified model to study the inventory management problem of a product and the coordination of the associated supply chain consisting of a single supplier and considerably many retailers in the presence of a secondary market. Specifically, consumer returns are allowed in the initial sales. They have introduced a secondary market to salvage the returns and the leftovers from the initial sales. In this secondary market, a discount price will be offered to the consumers but no returns are accepted. Moreover, between the primary and the secondary market, there is an internal market where retailers can trade among themselves so that they are able to adjust their inventory levels to prepare for the sales in the secondary market. They have studied the retailers' and the supply chain's inventory decision in this case and highlight the impact of the secondary market on the sales as well as on the supply chain coordination contracts. They have concluded that the secondary market helps increasing the total wholesale volume, but aggravates the incentive conflict between the retailers and the supply chain on deciding the optimal inventory levels, and then the supplier must offer more generous buyback contracts for coordination of the supply chain.

Hafezalkotob et al. [22] have investigated the coordinating role of the buyback contract in the distribution network. They have developed a model for illustrating how a manufacturer can use his initiative to organize retailers when they make decisions as independent actors. The candidate retailers are able to distribute products over geographically dispersed markets with stochastic demands. Each manufacturer's decision about selecting a set of retailers results in a unique distribution network design. Taking transportation and inventory costs into account, each candidate retailer determines order quantity to satisfy market demand, while the manufacturer specifies the wholesale price, pursuing uniform or retailer-specific pricing policies, depending on trade legislation. They have proposed the buyback contract for coordinating each design of the distribution network, and found that in the buyback coordination mechanism for retailer-specific pricing, if the buyback contract is more profitable than in the non-cooperative case, there is a win-win contract for the retailer and manufacturer.

Wang and Ren [23], using buyback contract, have studied the impact of demand disruptions upon the supply chain coordination, when the market retail price is fixed for the system which is comprised with one supplier and multiple vendors. Their paper presents the optimal strategy for supply chain to the interventions buy back and proposes an adjusted buyback contract that has anti-intervention ability. The authors have concluded that the buyback contract can coordinate one to many supply chain with fixed market price and the profit that the vendors obtained is larger at buyback contract than that at wholesale price contract.

ZENG and GAI [24] have investigated the supply chain with one supplier and multiple retailers who faces stochastic market demand. When the supply chain experiences a demand disruption during the planning horizon and the market scale changes sufficiently large, the supply chain cannot be coordinated. They first show that the coordination may be broken off by an emergent event, which make the demand disruptions, that is, it makes the demand distribution different from the assumption needs to achieve original supply chain's coordination.

\section{Coordination on multi-one supply chain by using buyback contract}

Hou et al [25] have studied a buyback contract between a buyer and a backup supplier when the buyer's main supplier might experience disruption risk. They have first defined supply disruption as the sudden stop of supply due to the occurrence of an unexpected event making the main supplier was totally unavailable, and then proposed a model considering one manufacturer and two suppliers: the main supplier is cheaper but prone to disruption risk and backup supplier is more reliable but an expensive. They investigated the differences of the contract parameters under recurrent supply 
uncertainty (SU) and demand uncertainty (DU), and In particular considered SU in the form of recurrent yield uncertainty and DU in the form of random demand. Their results show that these two types of uncertainty lead to different optimal strategies in terms of order quantity for the buyer and the return price for the backup supplier. The authors have developed a non-linear optimization model to determine the optimal values of buyer's order quantity and optimal buyback price under both supply and demand uncertainty.

Also be aimed at the coordination issue of a supply chain consisting of one retailer and two suppliers, a main supplier and a backup supplier (the main supplier' s yield is subject to disruption and the retailer faces a random demand.), $\mathrm{Hu}$ et al. [26] develop a combination of over production risk sharing and buyback contracts with a side payment to the backup supplier which can coordinate the supply chain under the risk of supply disruption. Research shows that two contracts with three components: overproduction risk sharing, buy-back, and a payment from/to the backup supplier cannot only coordinate our supply chain but also divide the whole chain's expected profit at any proportion among the three members. Numerical examples show that coordination can greatly benefit the retailer and the whole supply chain, and that the coordinated supply chain can achieve Pareto improvement by choosing the appropriate contract parameters.

Chen et al. [27] have considered a supply chain in which multiple suppliers bid for a single manufacturer's stochastic demand (the option to purchase from different suppliers helps the manufacturer hedge against demand risk). The contracts considered in their paper specify a wholesale price and a buy-back price. That is, suppliers are obliged to produce the required quantity prior to the realization of the actual demand and ship the entire quantity to the manufacturer. After demand materialized, suppliers buy back unsold inventory.

Leng and Parlar [28] have considered the coordination of an assembly supply chain (a multiple-supplier, single manufacturer): the suppliers determine their production quantities and the manufacturer chooses the retail price. They assume that the manufacturer faces a random price-dependent demand in either additive or multiplicative form. To improve the supply chain's performance, they have designed buy-back and lost-sales cost-sharing contracts, which achieve supply chain coordination. Under properly designed contracts, all supply chain members choose their equilibrium solutions and the maximum system-wide profit is realized.

\section{Conclusion}

In this paper, we have extensively reviewed the literatures of buyback contract in the context of supply chain coordination from the perspective of supply chain framework, such as one-one supply chain, one-multi supply chain and multi-one supply chains. We must do further research on the coordination of supply chain with multiple suppliers and multiple retailers setting.

In the otherwise, there are many variants of the contracts are implemented in the supply chain coordination mechanism, such as revenue sharing, options, VMI contract and quantity flexibility etc. The application of these contracts is worthy of our further exploration.

\section{Acknowledgement}

In this paper, The National Natural Science Fund (Project No. 701271043) sponsored the research

\section{References}

[1] Channel coordination. https://en.wikipedia.org/wiki/Channel coordination

[2] http://wiki.mbalib.com/wiki.

[3] Xiong H, Chen B, Xie J. A composite contract based on buy back and quantity flexibility contracts. [J]. European Journal of Operational Research, 2011, 210(3):559-567. 
[4] Wei J, Tang J. ANALYSIS ON THE STACKELBERG GAME MODEL AND RISK SHARING BASED ON BUYBACK CONTRACT [J]. Journal of Theoretical and Applied Information Technology, 2013, 48(2).

[5] Yao Z, Leung S C H, Lai K K. Analysis of the impact of price-sensitivity factors on the returns policy in coordinating supply chain.[J]. European Journal of Operational Research, 2008, 187(1):275-282.

[6] Yanhong Q, Yaxian Y, Guangxing W. Buyback contract Considering Fairness Preference under the Framework of Nash-Bargain in a Two Stage Supply Chain[J]. International Journal of Engineering Research and Applications (IJERA) 2013, 3(3): 1298-1305.

[7] Xu L, Li Y, Govindan K, et al. Consumer returns policies with endogenous deadline and supply chain coordination[J]. European Journal of Operational Research, 2015, 242(1): 88-99.

[8] Govindan K, Diabat A, Popiuc M N. Contract analysis: A performance measures and profit evaluation within two-echelon supply chains [J]. Computers \& Industrial Engineering, 2012, 63(1): $58-74$.

[9] Chen J, Bell P C. Coordinating a decentralized supply chain with customer returns and price-dependent stochastic demand using a buyback policy [J]. European Journal of Operational Research, 2011, 212(2): 293-300.

[10] Xiao T, Shi K, Yang D. Coordination of a supply chain with consumer return under demand uncertainty [J]. International Journal of Production Economics, 2010, 124(1): 171-180.

[11] Wu D. Coordination of competing supply chains with news-vendor and buyback contract [J]. International Journal of Production Economics, 2013, 144(1): 1-13.

[12] Yan N. Dynamic models and coordination analysis of reverse supply chain with remanufacturing [J]. Physics Procedia, 2012, 24: 1357-1363.

[13] Devangan L, Amit R K, Mehta P, et al. Individually rational buyback contracts with inventory level dependent demand[J]. International Journal of Production Economics, 2013, 142(2): 381-387.

[14] Güler M G, Keski M E. On coordination under random yield and random demand [J]. Expert Systems with Applications, 2013, 40(9): 3688-3695.

[15] Li Y, Wei C, Cai X. Optimal pricing and order policies with B2B product returns for fashion products[J]. International Journal of Production Economics, 2012, 135(2): 637-646.

[16] He X, Khouja M. Pareto analysis of supply chain contracts under satisficing objectives[J]. European Journal of Operational Research, 2011, 214(1): 53-66.

[17] Ping Y, Shen W, Lev B. Supply Chain Coordination with Group Buying Through Buyback Contract[C]//Proceedings of the Ninth International Conference on Management Science and Engineering Management. Springer Berlin Heidelberg, 2015: 223-233.

[18] Wang X B, Wang X H. Supply chain coordination based on buyback contract with fuzzy demand[C]//Machine Learning and Cybernetics, 2009 International Conference on. IEEE, 2009, 2: 839-843.

[19] Özen U, Sošić G, Slikker M. A multi-retailer decentralized distribution system with updated demand information[J]. 2006]. http://fp. tm. tue. nl/beta/publications/working\% 20papers/Beta_WP193.pdf, 2006.

[20] Sediri I, Nakade K. Competition in a decentralized supply chain under price and safety stock sensitive stochastic demand and buyback contract[J]. Journal of Advanced Mechanical Design, Systems, and Manufacturing, 2010, 4(3): 627-636.

[21] Huang X, Gu J W, Ching W K, et al. Impact of secondary market on consumer return policies and supply chain coordination[J]. Omega, 2014, 45: 57-70. 
[22] Hafezalkotob A, Makui A. Network design of a decentralized distribution supply chain: Analysis of non-cooperative equilibrium vs. coordination with discount or buyback mechanism[J]. Scientia Iranica. Transaction E, Industrial Engineering, 2014, 21(3): 988.

[23] Wang H, Ren Y. Supply Chain Coordination under Buyback Contract with Multiple Newsvendors[M]//Recent Advances in Computer Science and Information Engineering. Springer Berlin Heidelberg, 2012: 23-32.

[24] Fan-hui Z, Ru-dong G A I. Supply Chain Coordination with Multiple Competing Newsvendors[C]//Management Science and Engineering, 2007. ICMSE 2007. International Conference on. IEEE, 2007: 934-939.

[25] Fan-hui Z, Ru-dong G A I. Supply Chain Coordination with Multiple Competing Newsvendors[C]//Management Science and Engineering, 2007. ICMSE 2007. International Conference on. IEEE, 2007: 934-939.

[26] Hu F, Lim C C, Lu Z, et al. Coordination in a single-retailer two-supplier supply chain under random demand and random supply with disruption[J]. Discrete Dynamics in Nature and Society, 2013, 2013.

[27] Chen Y J, Sohoni M, Seshadri S. Procurement from multiple suppliers using options[R]. Working paper, New York University, New York, 2007.

[28] Leng M, Parlar M. Game-theoretic analyses of decentralized assembly supply chains: Non-cooperative equilibria vs. coordination with cost-sharing contracts[J]. European journal of operational research, 2010, 204(1): 96-10 